\title{
Short stature-webbed neck-heart disease syndrome
}

INSERM

\section{Source}

INSERM. (1999). Orphanet: an online rare disease and orphan drug data base. Short stature-webbed neck-heart disease syndrome. ORPHA:2865

Short stature-webbed neck-heart disease syndrome is characterized by short stature, intellectual deficit, facial dysmorphism, short webbed neck, skin changes and congenital heart defects. It has been reported in four Arab Bedouin sibs born to consanguineous parents. 